\title{
Cutaneous Melanoma Clinical Regional Lymph Nodes TNM Finding v8
}

National Cancer Institute

\section{Source}

National Cancer Institute. Cutaneous Melanoma Clinical Regional Lymph Nodes TNM

Finding v8. NCI Thesaurus. Code C136909.

A clinical finding about one or more characteristics of cutaneous melanoma, following the rules of the TNM AJCC V8 classification system as they pertain to stag ing of regional lymph nodes. The TNM clinical and pathologic regional lymph nodes classifications of cutaneous melanoma are not the same. TNM clinical regional lymph nodes findings are based on clinical/radiographic examination of the regional lymph nodes (clinically detected regional lymph node metastasis). (from AJCC 8th Ed.) 